\title{
Late rupture of transapically beating heart implanted neochords
}

Samuel Heuts, MD, ${ }^{\text {a,b }}$ Michal Kawczynski, BSc, ${ }^{a}$ Jules R. Olsthoorn, BSc, ${ }^{a}$ and

Peyman Sardari Nia, MD, PhD, a,b Maastricht, The Netherlands

From the ${ }^{a}$ Department of Cardiothoracic Surgery, Maastricht University Medical Center, Maastricht, The Netherlands; and ${ }^{\mathrm{b}}$ Cardiovascular Research Institute Maastricht (CARIM), Maastricht University, Maastricht, The Netherlands.

Disclosures: P.S.N. has a consultancy agreement with NeoChord Inc. All other authors have nothing to disclose with regard to commercial support.

Received for publication June 11, 2018; revisions received July 13, 2018; accepted for publication July 23, 2018; available ahead of print Oct 22, 2018.

Address for reprints: Peyman Sardari Nia, MD, PhD, Department of Cardiothoracic Surgery, Maastricht University Medical Center, Maastricht, The Netherlands (E-mail: peyman.sardarinia@mumc.nl).

J Thorac Cardiovasc Surg 2019;157:e27-9

$0022-5223 / \$ 36.00$

Copyright (C) 2018 by The American Association for Thoracic Surgery

https://doi.org/10.1016/j.jtcvs.2018.07.106

Video clip is available online.

Mitral valve repair on the beating heart with transapical implantation of GORE-TEX (W. L. Gore and Associates, Flagstaff, Ariz) polytetrafluoroethylene chords is a novel minimally invasive surgical technique for treatment of degenerative mitral valve disease. The procedure as performed with the aid of the NeoChord DS1000 Device (NeoChord, Inc, St Louis Park, Minn) has been described in several studies. ${ }^{1}$ Only a few cases of late rupture of polytetrafluoroethylene neochords used in conventional surgery have been reported. ${ }^{2}$ For this newer procedure, only periprocedural complications have been described, and late complications and durability still remain unknown.

\section{CASE REPORT}

We report the case of a 75-year-old female patient presenting with dyspnea (New York Heart Association functional class III). Preoperative transthoracic echocardiography showed severe mitral valve regurgitation (MR) with P2 prolapse, a good left ventricular function (LVF) with ejection fraction $62 \%$, absence of extensive ventricular dilatation (end-diastolic diameter of $45 \mathrm{~mm}$ ), and a pulmonary artery pressure of $55 \mathrm{~mm} \mathrm{Hg}$ (Video 1, 1.1). Transesophageal echocardiography (TEE) revealed an isolated P2 flail leaflet without extensive annular dilatation (Video 1, 1.2). On the basis of excellent anatomic and valvular eligibility, ${ }^{3}$ the patient was considered for a transapical beating heart approach by our multidisciplinary heart-team.

The procedure was performed under TEE guidance. Three NeoChords were implanted on the P2 leaflet (Video 1, 1.3). Intraoperative TEE after implantation showed a trace of MR and good LVF (Video 1, 1.4). The patient was discharged in good clinical condition on postoperative day 7. Transthoracic echocardiography at discharge confirmed the intraoperative imaging findings of trace MR and good LVF (Video 1, 1.5).

After 3 months, the patient was evaluated at our mitral outpatient clinic. The patient was in New York Heart Association functional class I and in good clinical condition. Follow-up transthoracic echocardiography showed good LVF and grade $1 \mathrm{MR}$ (Video 1, 1.6).

Five months postoperatively, the patient presented at the emergency department with dyspnea that had developed acutely during cycling. Transthoracic echocardiography and TEE revealed recurrence of severe MR (Video 1, 1.7) caused by neochordal rupture (Video $1,1.8$ ). The patient was prepared for urgent mitral valve repair. Intraoperatively, only dense adhesions were encountered at the apex of the left ventricle. On inspection, the tied knots of NeoChords and polytetrafluoroethylene felt pledget were still intact on the apex (Figure 1, $A$ and $B$, and Video 2) without apical disruption. After preparation of the apical access, however, we observed all NeoChords to be ruptured under
Central Message heart mitral valve repair still remains unknown.

See Editorial Commentaries pages e31 and e33. 


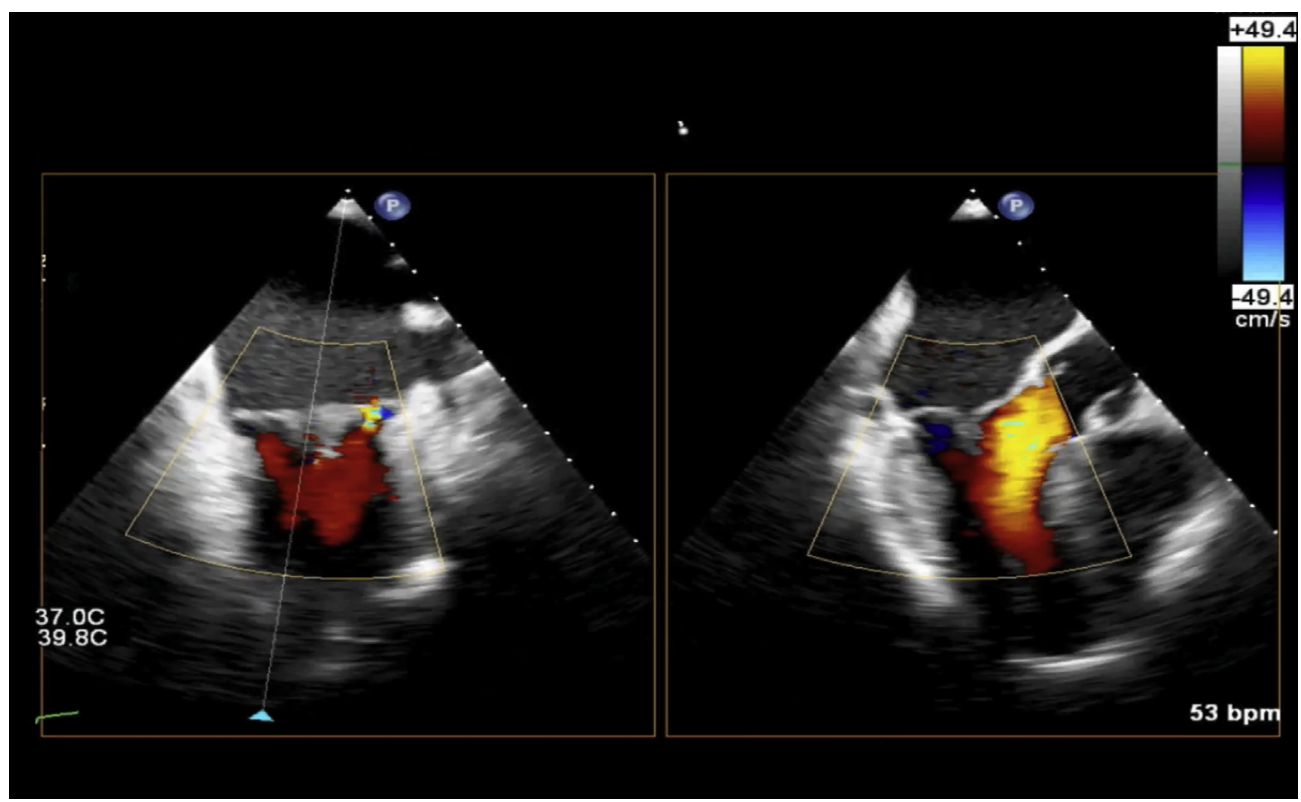

VIDEO 1. Echocardiographic evaluation. 1.1, Preoperative transthoracic echocardiography. 1.2, Preoperative transesophageal echocardiography. 1.3, Intraoperative transesophageal echocardiographic guidance during the procedure. 1.4, Intraoperative transesophageal echocardiography evaluation of the procedural result. 1.5, Transthoracic echocardiography at discharge. 1.6, Transthoracic echocardiography at 3 months of follow-up. 1.7, Transthoracic echocardiography at 5 months of follow-up revealing recurrent mitral regurgitation. 1.8, Transesophageal echocardiography at 5 months revealing a ruptured chord in the left atrium. 1.9, Intraoperative transesophageal echocardiography confirming good procedural result. 1.10, transthoracic echocardiography at maximum follow-up (1 year) showing trace of mitral regurgitation and good left ventricular function. Video available at: https://www.jtcvs.org/article/ S0022-5223(18)32469-3/fulltext.

the pledgets at the same level. The knots and the polytetrafluoroethylene felt pledgets were removed, and the apical wall was reinforced with a purse-string suture. Inspection of the mitral valve revealed intact and epithelialized NeoChords on the posterior leaflet (Figure 1, B, and Video 2). All NeoChords were removed, and mitral valve repair was performed (Video 2). Clamping time was 120 minutes, and cardiopulmonary bypass time was 161 minutes. Intraoperative TEE showed a trace of MR with good LVF (Video
1, 1.9). The patient was discharged in good clinical condition on postoperative day 6 . At follow-up of 1 year, the patient is free of symptoms and remains in excellent condition without recurrence of MR (Video 1, 1.10).

\section{DISCUSSION}

Durability of GORE-TEX polytetrafluoroethylene neochords in mitral valve surgery is well established, and 25-year results were published in 2013. ${ }^{4}$ GORE-TEX
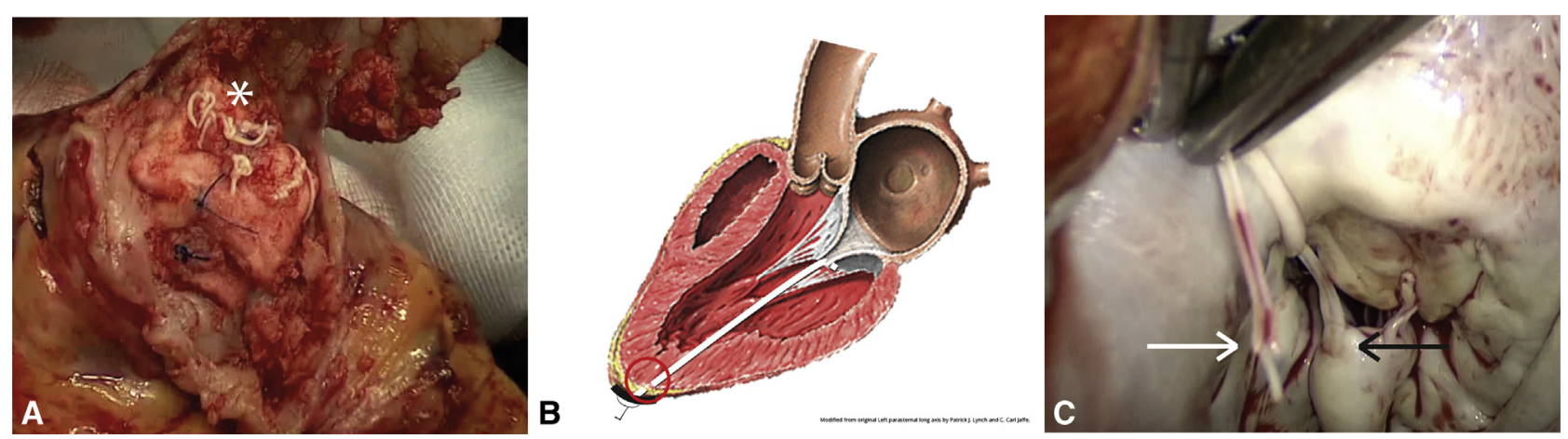

FIGURE 1. Intraoperative recording of findings. A, Intact knots on the apex (white asterisk). B, Illustration showing the location of the rupture along the implanted chord (pledget is illustrated in black at the apex, red circle surrounds rupture location). C, Intact NeoChord sutures on the posterior leaflet (black arrow) with a rupture in the chord itself (white arrow). 


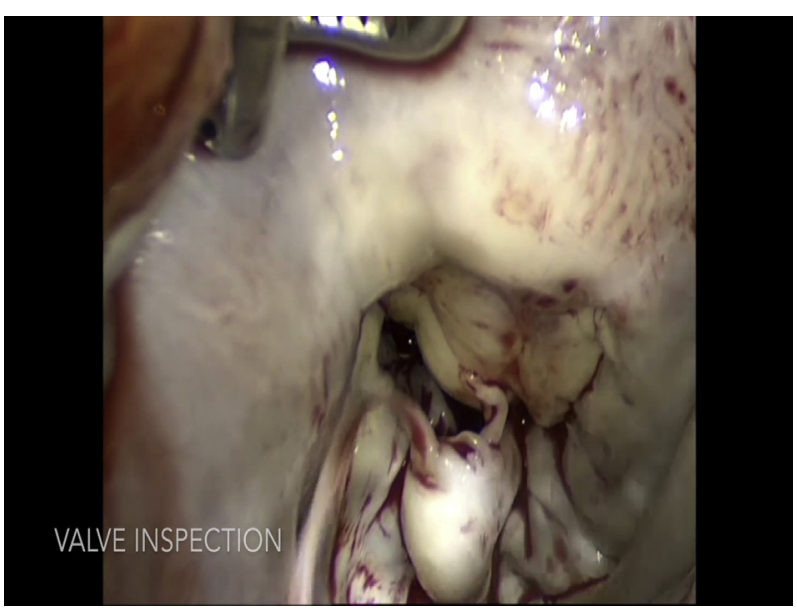

VIDEO 2. Intraoperative recording of findings. Intraoperative recording showing intact knots on the apex with rupture under the pledget and intact sutures on the posterior mitral valve leaflet. Video available at: https:// www.jtcvs.org/article/S0022-5223(18)32469-3/fulltext.

polytetrafluoroethylene chords have higher tensile strength than native chords and have $50 \%$ porosity. Only a few cases of chordal rupture have been reported in conventional surgery; these were caused by chordal calcification, probably as a result of this porosity. ${ }^{2}$

Because the rupture in this patient was localized at the apex below the knots of all the implanted chords at the same level, it is important to understand the underlying mechanism. It remains unclear how chordal forces are distributed along the neochords when tightened to the apex instead of to the papillary muscles and what consequences this has for the long-term durability of this procedure. In a recent animal study by Jensen and colleagues, ${ }^{5}$ chordal force distribution has been compared between papillary muscle implantation and apical implantation in pigs. Although there were no significant differences in peak and midsystolic tension, a significant $40 \%$ more inclined maximum slope of the tension curve $(\mathrm{dF} / \mathrm{dtmax})$ was observed in the apically implanted group. This means that tension increases more rapidly, resulting in more abnormal chordal tension fluctuations in these patients. ${ }^{5}$ This faster increase might be explained by absence of the shock absorbing effect of the papillary muscles or by increased length of the chords relative to papillary muscle implantation length (because the moment of force is dependent on the length of the arm), potentially leading to the incidental rupture of the chords.

\section{References}

1. Colli A, Manzan E, Zucchetta F, Bizzotto E, Besola L, Bagozzi L, et al. Transap ical off-pump mitral valve repair with Neochord implantation: early clinical results. Int J Cardiol. 2016;204:23-8.

2. Mori M, Pang PY, Hashim SW. Rupture of GORE-TEX neochordae 10 years after mitral valve repair. J Thorac Dis. 2017;9:E343-5.

3. Heuts S, Daemen JH, Streukens SA, Olsthoorn JR, Vainer J, Cheriex EC, et al. Preoperative planning of transapical beating heart mitral valve repair for safe adaptation in clinical practice. Innovations (Phila). 2018;13:200-6.

4. David TE, Armstrong S, Ivanov J. Chordal replacement with polytetrafluoroethylene sutures for mitral valve repair: a 25-year experience. J Thorac Cardiovasc Surg. 2013;145:1563-9.

5. Jensen H, Jensen MO, Waziri F, Honge JL, Sloth E, Fenger-Gron M, et al. Transapical neochord implantation: is tension of artificial chordae tendineae dependent on the insertion site? J Thorac Cardiovasc Surg. 2014;148:138-43. 